\title{
Assessing Students' Learning in Student-dedicated Treatment Rooms during Clinical Nursing Education
}

\author{
Louise Eulau ${ }^{1, *}$, Christina Sundman ${ }^{2}$, Max Scheja $^{3}$, Bjöörn Fossum ${ }^{1}$ \\ ${ }^{1}$ Sophiahemmet University, Box 5605, SE-114 86 Stockholm, Sweden \\ ${ }^{2}$ FOUnu - Jakobsbergs sjukhus, Birgittavägen 4, SE-177 31 Järfälla, Sweden \\ ${ }^{3}$ Stockholm University, SE-106 91 Stockholm, Sweden
}

Copyright (C) 2015 Horizon Research Publishing All rights reserved.

\begin{abstract}
In the present study, a model which enables a combination of individual, formative assessment with summative assessment in a group was introduced and evaluated in clinical education. Based on a qualitative design, the study embodies research based on participation and theory founded on empirically practical try-outs. The one-year project included two Swedish universities and related health care settings within one hospital. Three groups participated in the study. A survey was conducted at the end of each period to measure the students' learning attitudes. Narrative data from the surveys were compared to the impressions of the teachers using a hermeneutic approach. The implementation of assessing students in a group was successful in this study. The model is developed for a nursing program but has general qualities which, combined with a customized form of assessment, could be applicable to various educational programs.
\end{abstract}

Keywords Form of Assessment, Case Based Learning, Clinical Education, Curriculum, Formative Assessment, Clinical Nursing, Peer Learning, Student-dedicated Treatment Rooms

\section{Introduction}

Assessment of students in clinical nursing education is often described as a complex and complicated task [1]. Today most of the nursing universities in Sweden apply a summative, final assessment in a three-party conversation in which the student, the tutor and the teacher are involved. The transition from a traditionally trainee system to peer learning in student-dedicated treatment rooms during clinical training brings new challenges for assessing individual students' skills. Our aim was to develop a new model for assessing nursing students in group when undergoing clinical training in student-dedicated treatment rooms in the third term at the Degree Program in Nursing (180 higher education credits).

Training in student dedicated treatment rooms is characterized by: students are responsible for one treatment room; students mainly work in pairs; the focus is on the patients; reflection is important; time for reflection is scheduled; a logbook is used for reflections and comments; a clinical supervisor is to be nearby or present at all times, and the clinical supervisor's and lecturer's role is well defined [2, 3]. It is particularly suitable for students undergoing clinical training in the third term when the students mainly practice basic skills related to the patient care. The model makes it possible to encourage students from different disciplines and different universities to share their ideas and get feedback from them [3, 4]. Considered as a teaching and learning activity [5] this model is in line with current university teaching that recommend various forms of peer, cooperative or collaborative learning, particularly small group activities, to assist students to meet a variety of learning outcomes within an inter-professional context [6,7]. Learning is constructed as a result of the learner's activities $[7,8]$. To separate assessment from teaching ignores alignment and imposes a separate culture of assessment. A key issue in clinical training should therefore be a system that aligns teaching method and assessment to the learning activities.

Formative, continuous assessment can act as a tool for learning, contributing to the process and outcomes of learning [9]. In Sweden formative assessment is done by tutors or preceptors [10] while clinical lecturers alone are responsible for the final grading [11]. Most of the nursing universities also use summative assessment which is conducted in a three-party conversation in which the student, the tutor and the teacher are involved. Stockholm County Council has employed nurses who have a part-time assignment as adjunct clinical lecturers (ACL), whose mission is to work as a link between the university and the council-funded care to support the students and their tutors in clinical training [2]. One of the authors (Sundman) works as ACL in a suburb hospital focused on acute geriatric where students from different disciplines and different universities do their clinical education in patient-centered training, one author (Eulau) works as a clinical lecturer at one of the universities that collaborates with this hospital. In spring 
2013 they identified four items concerning the existing, final three-party assessment:

- The tutors' time consumed in the three-party assessment could be used in a better way in respect of patient-centered care as well as quality of the student's education. An ordinary assessment in three-party conversation takes about 45-60 minutes [1]

- It was difficult to identify students with special needs of support in time. These problems were overhanging if the tutor mainly relied on the final three-party conversation and did not let the assessment be a part of the learning process (formative).

- The assessment that came out of the final three-party conversation worked in some ways counter to the ideas of peer learning in the context of constructive alignment and gave the students the message that only individual achievement was valued.

- Students' dependence on their tutors was ambiguous. As the tutors are involved in the assessment of students' development in combination with the fact that nursing students in their future careers as nurses are usually employed in Stockholm County Hospitals, inevitably the students end up in a hierarchical advantage, or disadvantage, which made assessment unnecessarily prestigious and that the focus moved from the curriculum towards something else.

With these items in mind a model for assessing students in a group was requested. The Undergraduate Medical Program at Karolinska Institutet in Surgery once met a similar challenge with Case-Based Learning (CBL) in clinical training [12]. This method is characterized by its two learning phases: the preparation phase and the seminar. In the preparation phase, the individual students read and reflect on a specific case in preparation for the case seminar which promote peer learning [13-15]. Although the implementation of CBL was not satisfactory in that study [12], partly because of exposure of the weaknesses of the implementation process and the misalignment between CBL and the reigning teaching and learning regime, advantages which could be applied to the clinical training in nursing were uncovered.

Teaching for quality learning is ultimately an institutional responsibility [5]. But in clinical training it is always necessary to conduct a dialogue with the site in order to support person centered care $[3,16]$. The assessment form "Assessment of Clinical Education" (AssCE), a validated assessment instrument for assessment of student nurses' clinical education, is a tool that can be used for formative assessment during the whole clinical period with continuous feedback [11]( Figure 2). As both the university and the hospital were familiar with AssCE it became the natural starting point in giving structure and support during discussions about the level of development of a student's abilities in separate domains including cognitive, affective and technical skills, both in the formative and the summative phase of assessment.

The introduction has highlighted new challenges in the assessment of clinical training in student dedicated rooms. According to Constructive Alignment [5, 8] different didactic items have been presented, items which together hypothetically should contribute to the development of the assessment in clinical training. In simplistic terms, two questions have been raised: How can peer learning and formative assessment be used to replace the final three-party assessment? How can written cases be replaced by perceived cases so that they get an educational function in style with the approach used in the CBL?

\section{Materials and Methods}

\subsection{Design and Procedure}

Inspired of action research and action learning, the study has a theory-generating design founded on empirically practical try-outs with an emergent, data-driven methodology [17]. The starting point was a simplified, tentative model based on key aspects of different dimensions (figure 1). The study was based on a stepwise model consisting of planning, acting, observing, reflecting and re-planning [18].

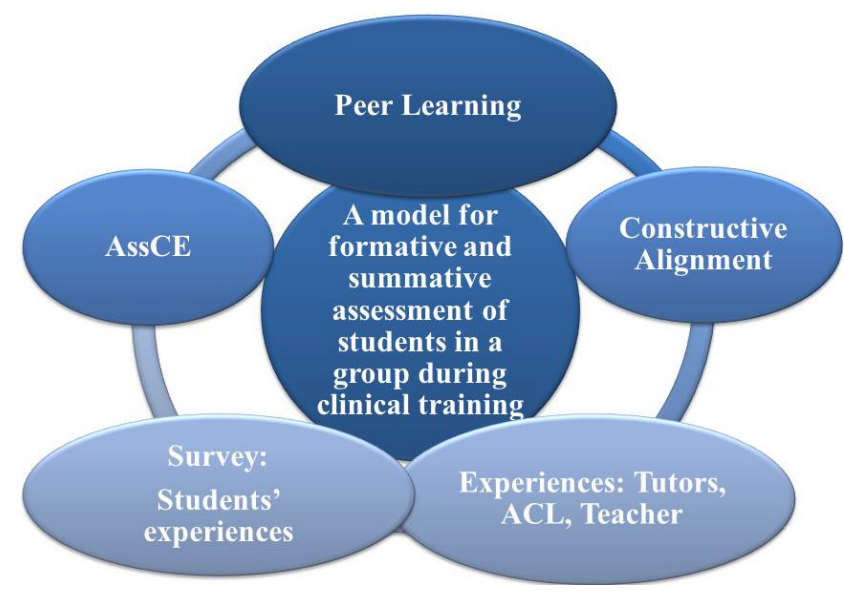

Figure 1. Tentative Model

The study was carried out over three terms from spring 2013 to spring 2014. Every term had two periods of clinical training that lasted for five weeks. The students in each period formed a group (fig. 3). In the second to fifth group, the above mentioned activities were followed with the addition of a short meeting between the teacher and each student. At that meeting the student could discuss anything about the clinical training and the assessment.

In order to meet the aim, a collaborative project was set up between the hospital and the university. Initially, the project was linked to a seminar series in university education in which three of the authors were engaged (Eulau, Fossum and Scheja). In spring 2013 two parallel activities were 
conducted, one focused on defining on theoretical and practical problems, and one focused on local levels to involve the staff at the hospital and ask for suggestions for developing the assessment.

According to Kemmis et al., [18] the next step, the phase of formative assessment, consisted of planning, acting, observing and reflecting: 1) The students and the staff were informed about the changing of assessment and how it corresponded to the students' curriculum; 2) both the tutors and the students were encouraged to maintain an ongoing dialogue with each other about course requirements and the student's individual development; 3) In the middle of the period (after two to three weeks) an appointment between each student and his or her tutor was made for a dialogue about the student's individual development based on AssCE. The tutor briefly reported the outcomes of the discussion to the teacher, 4) teacher and ACL planning or re-planning before the assessment seminar.

In clinical training students use their understanding to interpret evidence from individual meetings with patients [1]. Inspired by the CBL but with an exchange of the traditionally written case from which students use their understanding to interpret evidence, to orally retelling of perceived situations from the students' clinical training, the assessment sessions were treated as miniature case seminars (here called "assessment seminars"). To be adapted to the situation of summative assessment in clinics, the CBL-tradition's four distinguished features (the one person perspective, the narrative, open ended dilemmas and authenticity [13-15] were modified so that we could start from the basic conditions for the assessment of nursing students which are given in the instructions for use of the AssCE-form [11]( Figure 2).

The students were asked well in advance to prepare a nursing situation (a case) which they had experienced during their clinical training and describe it orally in a narrative way to the seminar. The idea was to introduce the seminar to a certain student's perspective. When the seminar began in group one (pilot), none of the students had prepared a specific case. However, the nursing care process as it is reproduced in the AssCE-form (Figure 2, second area) had been ongoing during the whole clinical training and the students could easily relate cases or short episodes from their training to one or more of the AssCE-form's five areas.

Each seminar lasted 50 minutes. In collaboration with the ACL, the teacher acted as a case facilitator and posed a question or a problem related to one of the AssCE-fields and asked the students to give their ideas or a proposed solution. Every AssCE fields were treated. In the beginning the questions were open-ended to stimulate the discussion around framed dilemmas which the students presented. According to the general idea with case based learning the teacher went on with deeper questions to help the learners see the situations described from a professional perspective.

\subsection{Participants and Data Collection}

The above described spiral of steps for planning, acting, observing, reflecting and re-planning, provided the basis for the data collection. Throughout the clinical training formative data were collected both from the ACL's observations guided by the AssCE form in assessment discussions at the halfway point, and from the feedback that came out of phone-calls, e-mails and discussions at local meetings between the ACL and the staff. Referred to the ethical guidelines of the Declaration of Helsinki [19] all participants were informed about the study in advance. It was optional to participate in the study.

The model for assessing students in groups was developed continuously over one year. With the ambition to measure the students' opinion about group assessing, the last ten minutes of the assessment seminars in group one, two and five were devoted to an anonymous survey in which the students were asked to finish the two sentences with the beginning "I like the ......" and "I wish ...". The completed sentences were translated and analyzed using a hermeneutic approach [20] in relation to relevant research on learning and teaching in higher education. The narrative, qualitative information that came out of the survey was organized into emerging themes according to Dick [17]. If a tutor had any concerns about a student, the teacher was contacted and an individual action plan could be made.

\subsection{Analysis}

Content analysis was used to compile information from the questionnaires. Recurring words or themes in the "I like answers" and the "I wish answers" were put together which opened up for thematic analysis involving a number of underlying comments on the assessment model [20].

\section{Results}

The reflecting on the consequences of the results from the survey in combination with the collective reflections on observations about the action mirrored by the ongoing discussions between the teacher, the ACL and the tutors, played an important role in deciding how we would exert our efforts most effectively. 


\section{Communication and teaching}

\begin{tabular}{||l|l|l|}
\hline $\begin{array}{l}\text { Inadequate achievement of goals } \\
\text { I. Communication and encounter } \\
\text { with patients }\end{array}$ & $\begin{array}{l}\text { Good achievement of goals } \\
\text { engaged manner, } \\
\text { Listens. Shows respect and empathy. }\end{array}$ & $\begin{array}{l}\text { Very good achievement of goals } \\
\text { difficulties. } \\
\text { Gives the paticnt adcquatc room in the } \\
\text { dialogue. }\end{array}$ \\
$\qquad \begin{array}{l}\text { inadequate } \\
\text { Datc of mid-coursc discussion: ......... }\end{array}$ & good \\
Date of final assessment: ..........
\end{tabular}

Figure 2. Example from the assessment form AssCE II form: the first area Communication and teaching and the first item (1/5) Communication and encounter with patients. The other areas are in order: II Nursing Care Process (5/5items), III Examinations and treatments (2/2 items); IV. Supervision of work and co-operation (4/4 items); V. Professional approach (5/5 items) [11].

Table 1, compilation of the answers of group 1-2 and 5 .

\begin{tabular}{|c|}
\hline $\begin{array}{l}\text { First group - three assessment seminars in May, } 32013 \\
\text { Compilation of sentences beginning with: I like (6/13 wrote more than one "I like-sentence") } \\
\text { 13/13 indicated satisfaction concerning the involvement and the commitment of the teacher, the ACL and the tutors. The ACL's } \\
\text { explicit clarification of the curriculum to the tutors was described as important thou it helped the students in their learning. } \\
4 / 13 \text { highlighted also the structure, the arrangements and the constructive alignment from the introductory day, during the training } \\
\text { in the student-dedicated treatment room to the assessment seminar. } \\
4 / 13 \text { described also obvious benefits of peer learning in the student-dedicated treatment rooms as well as in the assessment context. } \\
\text { The seminar was regarded as something more than just an occasion for control of obtained knowledge. The seminar inspired to } \\
\text { valuable discussions linked to the curriculum and also to advanced knowledge beyond the curriculum on the way towards a } \\
\text { profession as nurse. }\end{array}$ \\
\hline $\begin{array}{l}\text { Compilation of sentences beginning with: I wish } \\
\text { 10/13 requested clearer instructions, better routines and better information about different areas (not specific the assessment } \\
\text { model) linked to the clinical training. Eight of these students had also added some words that indicated that they were still happy } \\
\text { with the assessment seminar in general. } \\
\qquad 3 / 13 \text { were satisfied and did not want to change anything. }\end{array}$ \\
\hline $\begin{array}{l}\text { Second group - one assessment seminars in June, } 52013 \\
\text { Compilation of sentences beginning with: I like ( } 1 / 3 \text { wrote more than one "I like sentences") } \\
3 / 3 \text { students described benefits of peer learning in the student-dedicated treatment rooms as well as in the assessment context. They } \\
\text { meant that the seminar inspired to valuable discussions linked to the curriculum and also to advanced knowledge beyond the } \\
\text { curriculum on their way towards a profession as nurses. } \\
1 / 3 \text { answer highlighted also the benefits with the open dialogue that had been between tutor-ACL-teacher and student during the } \\
\text { clinical training. }\end{array}$ \\
\hline $\begin{array}{l}\text { Compilation of sentences beginning with: I wish } \\
1 / 3 \text { answer was a comment on the questions that were asked in the seminar. } \\
1 / 3 \text { answer mirrored a wish that did not relate to the assessment. } \\
1 / 3 \text { did not answer. }\end{array}$ \\
\hline $\begin{array}{l}\text { Fifth group - one assessment seminar in March, } 112014 \text { ( } 3 \text { students from the original university, two students from another nursing } \\
\text { university) } \\
\text { Compilation of sentences beginning with: I like } \\
5 / 5 \text { answers represented a clear positive attitude to assessment in groups. That the seminar was held with students from two } \\
\text { universities were described as positive for learning outcomes. The answers indicated that the seminar inspired to valuable } \\
\text { discussions linked to the curriculum and to advanced knowledge beyond the curriculum on their way towards a profession as } \\
\text { nurses. No differences in opinions / preferences could be inferred from the responses of students from the two universities. }\end{array}$ \\
\hline $\begin{array}{l}\text { Compilation of sentences beginning with: I wish } \\
5 / 5 \text { answers indicated satisfaction and no wishes of changes were presented. No differences in opinions / preferences could be } \\
\text { inferred from the responses of students from the two universities. }\end{array}$ \\
\hline
\end{tabular}




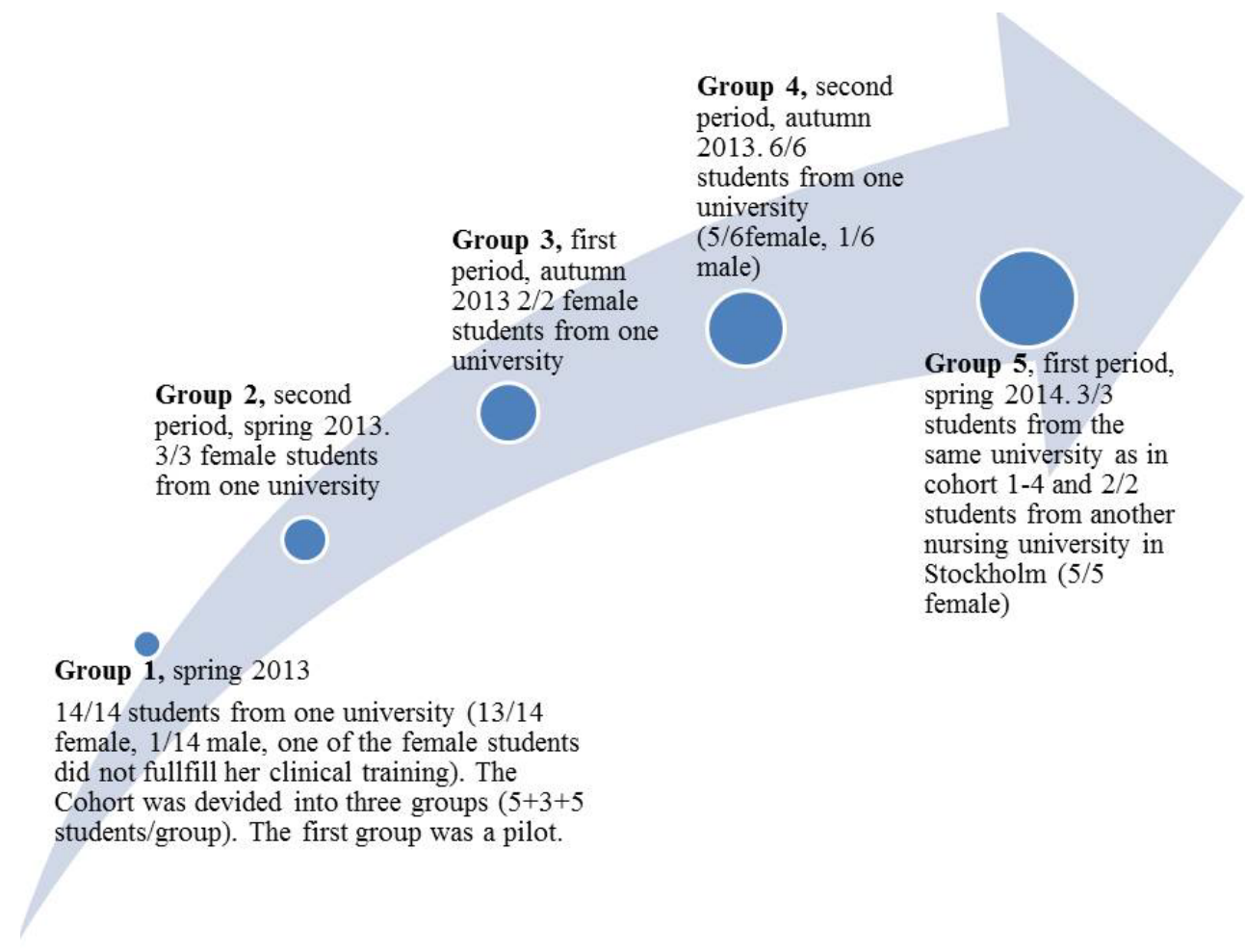

Figure 3. Overview of groups - every group was using AssCE

First group: acting, observing, reflecting and planning

The new way of assessing students was time consuming at the initial stage. The tutors had previous experience of assessing students' individual development in the three-party conversation but no previous experience of discussing the students' individual progress based on AssCE without the teacher's supervision. The tutors became frustrated when they did not understand what was expected of them in the assessment. Some of the tutors found it hard to prepare properly before the assessment discussion. Other tutors found the whole situation confusing because they did not feel prepared to assess students in the mid-course discussion.

The students in the first group had no previous experience of assessment in clinical training but they had some experience of working with Case Based Learning. If something was unclear to them about the assessment they mainly asked their tutors instead of contacting the teacher or the ACL. Even though the teacher and the ACL explicitly stated that the seminars were a complementary summative assessment to the formative assessment, the students in one of the wards doubted that they should get a "real assessment" (i.e. in a three-party conversation).

From the students' point of view, the tutors seemed mainly to be involved in the formative assessment in the patient-centered training in the student-dedicated treatment room. They did not realize that the tutors' ongoing contact with the teacher and the ACL guaranteed a dialogue which meant that tutors were still much involved in the assessment of students' development. The request of more personal feedback from the teacher seemed to mirror a lack of alignment between the assessment seminar and the formative assessment that the student had received from the tutor. In response, time was allocated for a brief meeting between the teacher and each student after the assessment seminar.

In response to the requests of clearer instructions and consistent information, the ACL arranged an extra information meeting in which the tutors got the opportunity to deal with experiences and get constructive feedback on their work and cooperation. Most of the tutors were relieved upon hearing that their (formative) assessments were to be regarded as a complement to the (summative) assessment seminar that was held by the teacher and the ACL. The time consuming aspect of the formative assessment still concerned some of the tutors. According to the assessment form AssCE in which each of the items ('factor' [11]) has a preprinted text for date of mid-course discussion, the re-planning meant that the assessment could be split up in any of the five areas of AssCE. In this way the formative assessment could be made in a time when an area or just an item of AssCE arose in the care and thus be an integrated part of the patient care as well as of the student's clinical training.

As the teacher and the ACL held the seminar in the absence of the tutors, the assessment discussions could be deepened without fear of exposing any knowledge gaps that could be miss favorable or embarrassing for students or tutors. The teacher could focus on the curriculum and the students did not end up in a hierarchical advantage, or disadvantage in front of the eyes of a potential employer. The climate in general was much more including and less prestigious in the seminar in comparison to our earlier experiences from assessments in three-party conversations. The experience was also that the students' level of 
understanding as well as their capacity to think quickly could be tested in a better way in the less prestigious milieu together with their course mates. Instead of being nervous, a majority of the students seemed to be relaxed, happy and proud to show their skills under and after the assessment seminars.

Compared to what is said above that learning activities should support and encourage learning aligned with learning outcomes and to the surveys' many positive "I like sentences", the assessment seminars could encourage peer learning in the assessment-situation with future reach beyond the curriculum.

\section{Second group: acting, observing, reflecting and planning}

In the second period had some routines reprocessed and the tutors had adapted their operations and disposed their time in relation to the changes. The students in the second group had one previous experience with assessment in a three-party conversation (from another hospital) and they had experience of working with CBL as well. Their responses reflected none of the uncertainty regarding the principles of the assessment process that were faced in the first group.

Each student took the opportunity to orally get personal feedback in addition to the seminar. This time, the students' "I wish-answers" mainly dealt with circumstances that in some ways were beyond the assessment process. The students as well as the tutors seemed to be more comfortable to handle the formative part of the assessments.

Early in the period one tutor signaled some concerns about a student. With the help of an individual action plan provided by the teacher, the student could reach the curriculum before the assessment seminar.

Third to fifth group: acting, observing, reflecting and planning

Two assessment seminars were held during the autumn of 2013. By that time the staff at the hospital was familiar with the new way of assessment and no new studies were made on group number three and four. Gradually, as the scope of the work increases, the group may expand its membership [18]. In spring 2014 three students from the first university and two students from another nursing college in Stockholm made clinical training at the same time at the hospital. As the students were in term three, had similar curriculum and were familiar to the same assessment form (AssCE), they became a fifth group. The aim was to investigate the possibilities to assess students from different universities within the same seminar.

The reflections on the data collected from discussions, the student survey and the formative and summative assessment with the fifth group, suggest that it is possible to assess students from two different universities in the same manner as described above, provided that the students have similar curricula and use the same assessment form. However, more time was needed to introduce the new way of assessment in group to the other university and its students. Although the students had separate meetings with their tutors and the teacher, no conclusions can be made. To act on broader fronts and develop the way of assessing in group, but still let the control rest with tutors, students, $\mathrm{ACL}$ and teacher, more refined plans for actions with more involvement of the various stakeholders at the executive level are required. Moreover, additional studies have to be made to further investigate the possibility to assess students from different universities within the same group.

\section{Discussion}

In a situation of assessment, every meeting/case can be used as an occasion to interpret impressions, performances and evidence to evoke the type of thinking necessary for understanding in nursing [11]. Applied to our experiences from the study, the assessment seminars tested those learning outcomes that encourage teamwork rather than single student efforts. By giving each student separate feedback with relevant suggestions for improvement it could be clarified how the experiences from the clinical training could be used in the future. The results of the study reveal that a combination of formative and summative assessment of students in student-dedicated treatment rooms can be implemented in peer learning throughout the clinical training. The result also indicates that students' joint active participation in their assessment facilitated their learning because the seminars stimulated discussions, reflections, and peer-learning.

Within the institutional and social milieu at the site, staff allocated tasks to students, gave feedback to them and marked assessments. These kinds of activities have a direct impact on the quality of student learning [6]. Our experience is that practical experiences from clinical training can be translated into theoretical frameworks which can suggest ways of designing assignments that support integrative personal understanding.

Moore over it allowed valuable time for problem solving, creating, critiquing, and synthesizing with peers and professors in a flexible, dynamic, engaging, non-judgmental, and trusting environment. However, oral assessment can create considerable anxiety [6]. Quite early in each assessment seminar (group 1-5) the students themselves began to ask follow-up questions to each other. If the answers spontaneously came up in a different order, the assessment process considered the quality of the whole performance. At the end of the seminar, the case was summarized by a joint effort of the teacher and the students. Here the teacher built the assignment and assessment tasks into a recursive cycle which allowed comments on the students' presentations to be used in the future, i.e. feed forward [6]. Effective seminars also depend on good preparation by the teacher. A continuous dialogue between teacher, ACL, tutor and student during the clinical training helped us in preparing helpful materials and thinking about ways of stimulating discussion. Assessments based on a 
validated assessment instrument may contribute to making the students' transition into the future profession easier. In this particular study the AssCE-form was used. However any validated assessment instruments with a direct link to the curriculum of the training could be used in any education that involves clinical training. Our experience is that the optimal size of an assessment seminar is five students, two teachers or one teacher and one ACL. Within mass higher education it is proving difficult to maintain the quality of feedback that students receive.

Meyer and Land [21] argue that, within specific disciplines there exist 'threshold concepts' that lead to new and previously inaccessible ways of thinking about something. Caring under clinical training, can be thought of as a threshold concept because superimposed on the common sense or intuitive understandings of care, with which students commence their program, are the experiences of treating patients within a medical framework. In order to on the one hand to stimulate reflection and continuous professional development and on the other hand to enable the university to keep control and certify the students' level of knowledge, the study shows that this can be possible if the assessment process is in line with the notion of constructive alignment [5].

In the ambition to ensure not only sufficient learning outcomes but also to provide meaningful comments on the work, we suggest that peer discussion of assignments between students is supplemented by systematic formative assessment given by the tutors. By also implementing an assessment seminar, the assignment and assessment task can be built into a recursive cycle which allows comments on the work done to be used in later clinical trainings and in future careers. In conclusion, this means that each student is provided with both feedback and feed forward [6].

Formative assessment that could be divided as described above (see Results - first group) combined with assessments in seminar makes it possible to arrange and rearrange the staff's resources. By extension, this means that the tutors can devote more of their time for patients and students in the direct patient care at the hospital.

One of the limitations of this study lies in the limited study sample and in particular for the small number of students in the second to fifth group. On the other hand, it must be said that only small adjustments were made after the first group. Furthermore it is important to keep in mind that the study is operating within the qualitative research paradigm and therefore is not aiming at generalization but, instead, at its applicability by stakeholders who perceive themselves to be in related situations. The strength of this study lies in the fact that it focused on a common area in clinical training: curriculum development through the introduction of new learning activities. More specifically, it contributes thorough implications for practice for all those engaged in clinical training.

\section{Conclusions}

We believe that the study results indicate an overall successful implementation of assessment seminars into the clinical training in student-dedicated treatment rooms in term three of the Degree Program in Nursing. We also believe that students' joint active participation in their assessments in the continuously made assessments in dialogue with their tutors throughout the clinical training combined with an assessment seminar at the end of the period can facilitate students' adoption of a deep approach to learning with the potential to develop an understanding that goes beyond the curriculum.

Although the implementation process of the assessments was successful, we believe that a continuous transparency in connection to the tutors' assessment and to assessments made in the seminars and the students' self-evaluations are important keys in successfully implementing assessment seminars as a student-activating learning activity into a clinical curriculum.

\section{Acknowledgements}

We are very grateful to the staff at Jakobsbergs' Hospital and to the scholar seminar at Sophiahemmet University for their appropriate and constructive suggestions to improve this template.

\section{REFERENCES}

[1] Lofmark A, Thorell-Ekstrand I. An assessment form for clinical nursing education: a Delphi study. Journal of advanced nursing. 2004 Nov;48(3):291-8. PubMed PMID: 15488043. Epub 2004/10/19. eng.

[2] Engström A. Dimmornas bro : en berättelse om konstruktionen och iscensättandet av kliniska adjunkter. Västerås: School of Education, Culture and Communication, Mälardalen University; 2012.

[3] Staun M, Bergstrom B, Wadensten B. Evaluation of a PBL strategy in clinical supervision of nursing students: patient-centred training in student-dedicated treatment rooms. Nurse education today. 2010 Oct;30(7):631-7. PubMed PMID: 20061069. Epub 2010/01/12. eng.

[4] Birgersson Å-M, Sundman C. Verksamhetsförlagd utbildning på nya vilkor: Sjuksköterskors erfarenheter av handledning i en studentsal. 2012.

[5] Biggs JB. Teaching for quality learning at university : what the student does. London: the Society for Research into Higher Education :; 2003.

[6] Entwistle N. Teaching for understanding at university : deep approaches and distinctive ways of thinking. Houndmills, Basingstoke: Palgrave Macmillan; 2009.

[7] Boud D, Cohen R, Sampson J. Peer learning in higher education: Learning from and with each other: Routledge; 2014. 
[8] Biggs JB, Tang CS-K. Teaching for quality learning at university [Elektronisk resurs]. : what the student does. Maidenhead: Open University Press; 2011.

[9] Weurlander M, Söderberg M, Scheja M, Hult H, Wernerson A. Exploring formative assessment as a tool for learning: students' experiences of different methods of formative assessment. Assessment \& Evaluation in Higher Education. 2012;37(6):747-60. PubMed PMID: 79379255.

[10] Lofmark A, Thorell-Ekstrand I. Evaluation by nurses and students of a new assessment form for clinical nursing education. Scandinavian journal of caring sciences. 2000;14(2):89-96. PubMed PMID: 12035281. Epub 2002/05/31. eng.

[11] Lofmark A, Thorell-Ekstrand I. Nursing students' and preceptors' perceptions of using a revised assessment form in clinical nursing education. Nurse education in practice. 2014 May;14(3):275-80. PubMed PMID: 24140366. Epub 2013/10/22. eng.

[12] Nordquist J, Sundberg K, Johansson L, Sandelin K, Nordenstrom J. Case-based learning in surgery: lessons learned. World journal of surgery. 2012 May;36(5):945-55. PubMed PMID: 22223292. Epub 2012/01/10. eng.

[13] Barnes LB, Christensen CR, Hansen AJ. Teaching and the case method : text, cases, and readings. Boston, Mass.: Harvard Business School Press; 1994.
[14] Wassermann S. Introduction to case method teaching : a guide to the galaxy. New York: Teachers College Press, Teachers College, Columbia University; 1994.

[15] Garvin DA. Teaching executives and teaching MBAs: Reflections on the case method. Academy of Management Learning \& Education. 2007;6(3):364-74.

[16] Manninen K, Henriksson EW, Scheja M, Silen C. Patients' approaches to students' learning at a clinical education ward-an ethnographic study. BMC medical education. 2014;14:131. PubMed PMID: 24989155. Pubmed Central PMCID: PMC4094893. Epub 2014/07/06. eng.

[17] Dick B. What can grounded theorists and action researchers learn from each other. The SAGE handbook of grounded theory. 2007:398-416.

[18] Kemmis S, McTaggart R, Nixon R. The Action Research Planner [Elektronisk resurs] : Doing Critical Participatory Action Research2014.

[19] Ndebele P. The Declaration of Helsinki, 50 years later. Jama. 2013 Nov 27;310(20):2145-6. PubMed PMID: 24141794. Epub 2013/10/22. eng.

[20] Patton MQ. Qualitative research \& evaluation methods. London: SAGE; 2002.

[21] Meyer J, Land R. Threshold concepts and troublesome knowledge: linkages to ways of thinking and practising within the disciplines: University of Edinburgh UK; 2003. 